\title{
Seasonality and Tectonic Influences on Subduction Zones for Ultra-Deep Earthquakes
}

\author{
Marilia Hagen', Anibal Azevedo \\ ${ }^{1}$ Instituto de Física, Universidade Federal Fluminense, Niterói, Brazil \\ ${ }^{2}$ Faculdade de Ciências Aplicadas da Unicamp, Limeira, Brazil \\ Email: marhagen@indiana.edu, anibal.azevedo@fca.unicamp.br
}

How to cite this paper: Hagen, M. and Azevedo, A. (2018) Seasonality and Tectonic Influences on Subduction Zones for Ultra-Deep Earthquakes. Open Journal of Earthquake Research, 7, 269-284. https://doi.org/10.4236/ojer.2018.74014

Received: October 25, 2018

Accepted: November 25, 2018

Published: November 28, 2018

Copyright $\odot 2018$ by authors and Scientific Research Publishing Inc. This work is licensed under the Creative Commons Attribution International License (CC BY 4.0).

http://creativecommons.org/licenses/by/4.0/ (c) (i) Open Access

\begin{abstract}
Our previous research has found that deep or very deep earthquakes can be influenced by different seasons of the year. It also indicates that other factors may impact the seasonality in addition to these external parameters. This would explain why the response from Northern Hemisphere and Southern Hemisphere for the seasons is different. In the current research, we will focus on very deep earthquakes over a very long period, 1950-2017, which have high magnitude of $M \geq 6$ with depth $\geq 500 \mathrm{~km}$ and named ultra-deep earthquakes (UDQ). We will separate such events by coordinates of each subduction area located in the Pacific Ring of Fire to find which effects the seasons have on these specific areas. Former tomographic studies in such regions pointed out that each area mentioned had systematic differences in the slab configuration along arcs. Our conclusions showed that those discrepancies may influence the enhancement of earthquakes in some seasons or months.
\end{abstract}

\section{Keywords}

Ultra-Deep Earthquakes (UDQ), Subduction Zones, Tectonics

\section{Introduction}

Our previous works [1] [2] showed that there was a correlation between the seasons of the year and the deep or very deep earthquakes. According to those studies, the seasonality of the earthquakes also depends on the location we are searching. The subduction locations examined were displayed by their different coordinates and positions in relation to the globe. We also discussed the importance of dividing into the Northern or Southern Hemispheres, which presented some idiosyncrasies when also calculating by area. 
For example, North Pacific obeyed the following equation for enhancement of quakes in the different depths we worked in [2]:

Number of Quakes a 1/Depth

The area verified this relationship; hence, the deepest quakes observed $\geq 500 \mathrm{~km}$ had the fewest occurrences when compared with the shallower depths. The highest occurrences of quakes for the North Pacific are at the depths $100-200$ $\mathrm{km}$ where $60 \%$ of events took place.

To the South Pacific, we got an interesting result of $64 \%$ of quakes occurring at the level $100-200 \mathrm{~km}$. This number decreased for lower depths, or $>200 \mathrm{~km}$, and abruptly at the depth $>500 \mathrm{~km}$ where $21 \%$ of all events occurred.

The last region searched was South America with $87 \%$ of occurrences at the depth $100-200 \mathrm{~km}, 11 \%$ at $200-300 \mathrm{~km}$, a discontinuity between $300-500 \mathrm{~km}$ with the lack of available quakes records, and, finally, below $500 \mathrm{~km}$ just $2 \%$ of the total occurrences of earthquakes. Our calculations lead to the conclusion that South America has a possible anomaly in their tectonics that would explain the total absence of earthquakes at depths $300-500 \mathrm{~km}$.

The following paper [2], isolated the ultra-deep earthquakes around the world in the regions North Pacific, Philippines, South Pacific, and South America, and attempted to determine if there was any connection between seasonality and the apparent rise and fall of the number of events along the time period 1999-2017.

We concluded that this time period of just 18 years was not enough to prove there was a real connection, if any, between seasons and hazards; however, we did find a slight correspondence between seasons and the enhancement of earthquakes.

In the current literature, a paper [3] has been studying the same problem; however, they made a mistake in considering the seasons as the same for the entire world. It was an elementary mistake considering that it is winter in the Southern Hemisphere when it is summer in the Northern Hemisphere, and vice-versa. Another mistake was to consider magnitudes of only M7 or higher. We already discovered that, depending on the subduction zone studied, the larger magnitude occurrences had smaller values.

Preliminarily in this research, the initial conditions will include only the following: earthquakes $M \geq 6$ and the depths $\geq 500 \mathrm{~km}$. The worldwide subduction zones were divided into five areas with coordinates delimiting the areas. This narrowed occurrences and may be ignoring events that occurred outside of those spaces. The time period is 1950-2017, according to the public catalogs currently available. Longer time frames for UDQs are necessary since there are fewer occurrences of those events which allows for the possibility of finding any correlation with seasons.

Nevertheless, it is impossible to take the raw data of each area and associate or compare it with other areas. Each region examined saw variations in the number of quake events, some of which were higher or lower to ultra-deep events (UDQ). In some places, there are also more occurrences with foreshocks and af- 
tershocks than others. For a comparison between the regions and quakes, it is necessary to consider monthly averages, as we will see later.

After those calculations, the results by each month can be associated with a season and a subduction area, depending on the hemisphere in which it occurred or did not occur.

Another issue in this research is about the tectonics for the area examined. The research considered only the areas around the circum-Pacific where UDQ are more intense with higher frequency of events. The new step in this study was to add some tectonics characteristics for the five different areas, two in Northern Hemisphere and three in the Southern Hemisphere, and consider the earthquakes occurring in all of the mat depths $\geq 500 \mathrm{~km}$. The last initial condition concerns the magnitudes of the deepest events; it was taken as $M \geq 6$ since the deepest quakes depths around the world occur around Fiji and Tonga where large magnitudes start at M6.

Here, a primary objective is to associate season and possible connections with the UDQ events and high magnitudes, and to understand how the tectonics could delay or enhances the occurrences for each month calculated.

The paper first shows a description of the subduction zones and the tectonics for each area analyzed. It also displays zones worldwide where these hazards mostly occur; however, not all the areas were covered.

Next, a mathematical model is applied on the data available to find out how the events vary along the months in a year. Although it is considering the events by month, the range of time is 1950-2017, a period of $\sim 67$ years. The objective is to discover during which months of the year in an area search there were more UDQ happening and which season those months fell in.

Subduction zones in the Northern Hemisphere showed similar responses to the seasons and Southern less resemblances result that we regarding to the tectonics in the Southern.

For example, the South American area has recently found anomalies [2] which do not exist in the Northern Hemisphere. The subduction region of Fiji experiences the deepest events on the planet; therefore, it seems an indication that these areas will be less susceptible to change with the seasons in the same way as the Northern were.

Here we are conducting an initial study around the circum-Pacific region with some narrow initial conditions for the quakes. We plan to soon expand our study to find more promising results in predicting UDQ.

\section{Former Theories for the Circum-Pacific Areas Studied}

There are some pre-conceived theories about subduction zones. One [4] of them states there are four types: 1) as lab stagnant above discontinuity at the middle, 2) a slab penetrating the $660 \mathrm{~km}$ discontinuity, 3) a slab trapped in the uppermost lower mantle, and 4) a slab descending well into the deep lower mantle. This theory satisfies most of the regions where there are the deepest depth 
earthquakes; however, they do not include an explanation for the location around Fiji, which is the only location that experiences earthquakes at a depth of 700 $\mathrm{km}$. Also, the theory is independent of time in seismic activity. The history of events is important because the deepest earthquakes happened at the following depths around the Ring of Fire: $686 \mathrm{~km}$ in 2015 in Japan, $677 \mathrm{~km}$ in 2013 in Vanuatu, $676 \mathrm{~km}$ in 2002 in the Santa Cruz Islands, $675 \mathrm{~km}$ in 2000 in Banda Sea, $678 \mathrm{~km}$ in 2000 in the Philippines, $678 \mathrm{~km}$ in 1998 in the Sea of Okhotsk, and $673 \mathrm{~km}$ in 2016 in Indonesia.

Another depth is analyzed $(\geq 700 \mathrm{~km})$ with the deepest quakes, and the only region which presents such depth is at the neighborhood of the Fiji Islands. The last quake occurred in 2008 at the depth $700 \mathrm{~km}$, and the deepest depths were $721 \mathrm{~km}$ in 2007 in Fiji and at $735 \mathrm{~km}$ in 2004 in Vanuatu. Analyzing the period of those UDQ it was possible to detect the uniqueness of the area near Fiji Islands. In addition, the magnitude of deep events there is generally M6 for the larger quakes.

\section{Definition of Coordinates Locations and Seasons by Hemisphere}

Our new step for UDQ is to consider the following parameters: depths $\geq 500 \mathrm{~km}$, magnitudes $M \geq 6$, and different subduction locations. Two of these locations are at the North Hemisphere and the three others are at the Southern Hemisphere. They are North Pacific and Philippines for the Northern, South Pacific (Indonesia), South America, and Fiji for the Southern.

The coordinates to construct the maps were displayed in Table 1 .

The coordinates make a subdivision of areas where UDQ are happening. Although it is clearly defined at the Northern and Southern Hemisphere, it is not possible to comprise all the locations with deepest earthquakes within these coordinates. For example, the region around Papua and Solomon Islands were not included in this study mainly due to the small number of events that occurred in the past 67 years that meet the required initial conditions; therefore, the events presented in the areas delimited in the following figures show exactly where the UDQ was recorded in the catalogued data.

The following table, Table 2, displays the season by Northern and Southern Hemisphere. This will allow us later to easily connect the data found by month and the corresponding season by hemispheres.

The following section is regarding the construction of the maps with some consideration of the tectonics in each area studied.

\section{Construction of the Maps and Tectonics Views}

The initial part of this study divided the subduction zones according to the hemisphere in which they occurred. Papers on these topics [5] [6] [7] had no means to compare results for all the subduction zones studied. They isolated a subduction zone and understood their characteristics limited their observations much. None of the works mentioned allowed for the analysis of the set of 
Table 1. Coordinates for each area analyzed divided by Northern and Southern Hemisphere.

\begin{tabular}{cc}
\hline North Hemisphere & Coordinates \\
\hline North Pacific & $67.067 \mathrm{~N}, 30.449 \mathrm{~S},-144.844 \mathrm{E},-226.934 \mathrm{~W}$ \\
Philippines, Mariana's & $20.633 \mathrm{~N}, 1.862 \mathrm{~S},-223.94 \mathrm{E},-252.246 \mathrm{~W}$ \\
South Hemisphere & $10.207 \mathrm{~N},-16.236 \mathrm{~S},-184.922 \mathrm{E},-263.672 \mathrm{~W}$ \\
South Pacific & $5.545 \mathrm{~N},-53.54 \mathrm{~S},-65.215 \mathrm{E},-87.539 \mathrm{~W}$ \\
South America & $-9.243 \mathrm{~N},-35.29 \mathrm{~S},-197.227 \mathrm{~W},-119.18 \mathrm{E}$ \\
\hline
\end{tabular}

Table 2. Season periods for Northern and Southern Hemispheres.

\begin{tabular}{cccc}
\hline Northern Hemisphere & Range & Southern Hemisphere & Range \\
\hline Spring & March 1-May 31 & Spring & Sept 1-Nov 30 \\
Summer & Jun 1-Aug 31 & Summer & Dec 1-Feb 28 \\
Fall & Sept 1-Nov 30 & Fall & March 1-May 30 \\
Winter & Dec 1-Feb 28 & Winter & Jun 1-Aug 31 \\
\hline
\end{tabular}

subduction areas; on the contrary, they studied one or another separate region. To make our study feasible, we would need surveys that could show the locations of very deep earthquakes and compare the characteristics and differences of each one of them with respect to the others.

Our paper constructed the following maps with the data displayed in [8] and [9] in the period from 1950-2017. This first part of the investigation considered all Magnitudes $>2.5$ as the catalogs allowed.

The first location is the North Pacific, which is comprised of the Sea of Okhotsk, Russia, Japan, China sea, Philippines Sea, and Northern Mariana Islands. The coordinates are listed in Table 1. Figure 1 displays the events $\geq 500 \mathrm{~km}$ at Okhotsk, Russia, and the Sea of Japan. The period researched presented only 52 tremors. The deepest occurred WNW of Chichijima, Japan in May/June 2015 at depth $\geq 670 \mathrm{~km}$. The deepest depth event encountered occurred in 1988 near Mindanao, Philippines, and the region examined for this event is located around the Philippines Sea and is divided in a straight line parallel to the China Sea and other paths following up the Mariana Islands (see Figure 2).

As expected, the number of events is decaying with depths along the time range as Equation (1) to those subduction areas. For the Southern Hemisphere, there is the South Pacific (Indonesia and surroundings), South America, and Fiji.

South America, as described in the two other papers, displayed three central regions with points where the UDQ occurrences are more frequent. One area is Peru's Amazon region, another in Bolivia, and the third in Southern Argentina (see Figure 3). Santiago del Estero is the furthest point with UDQ events. These three areas are separated for spaces where there is a lack of occurrences of earthquakes $\geq 500 \mathrm{~km}$ depth. The deepest tremor had a small magnitude (3.7) and depth of $674.2 \mathrm{~km}$. 


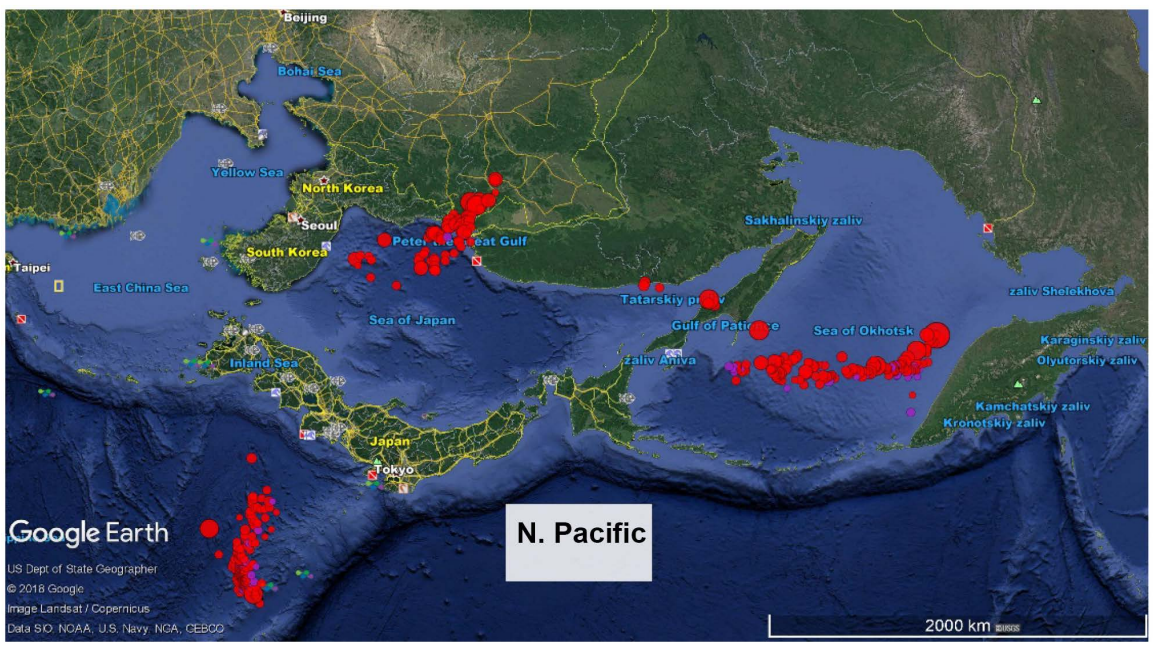

Figure 1. Earthquakes depth ( $\geq 500 \mathrm{~km})$ around North Pacific, including Sea of Okhotsk, Russia, and Sea of Japan, $\mathrm{M} \geq 2.5$, period 1950-2017.

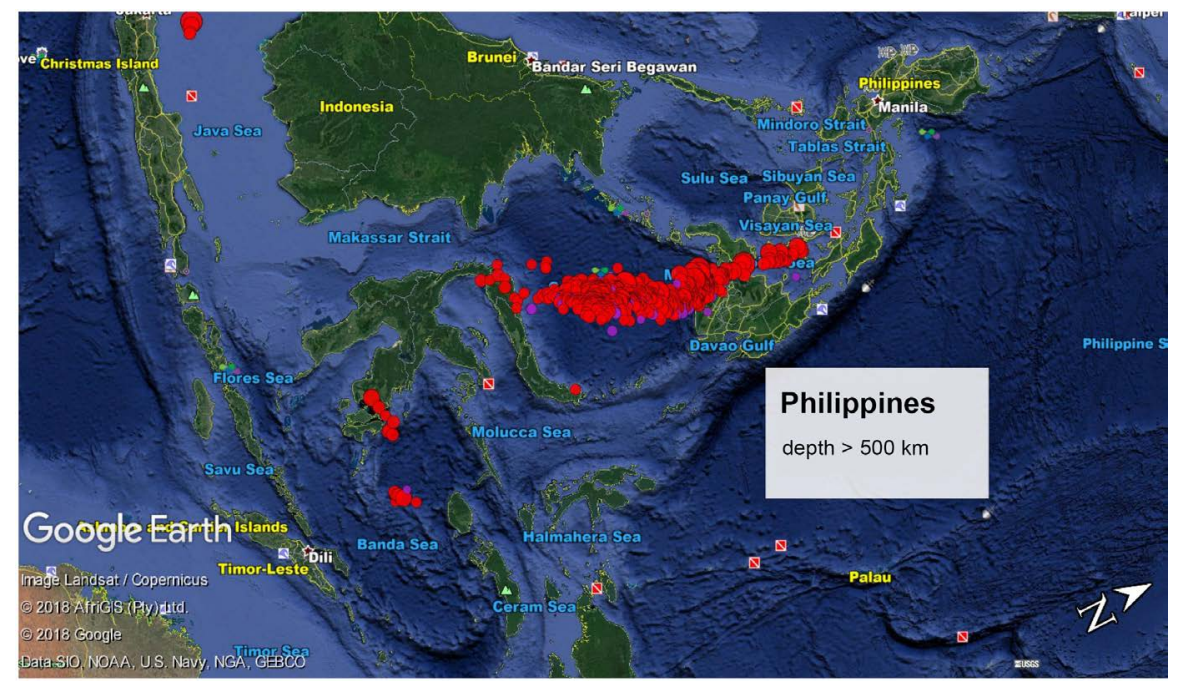

Figure 2. Quakes 1950-2017, depth $\geq 500 \mathrm{~km}$, Philippines, $M \geq 2.5$.

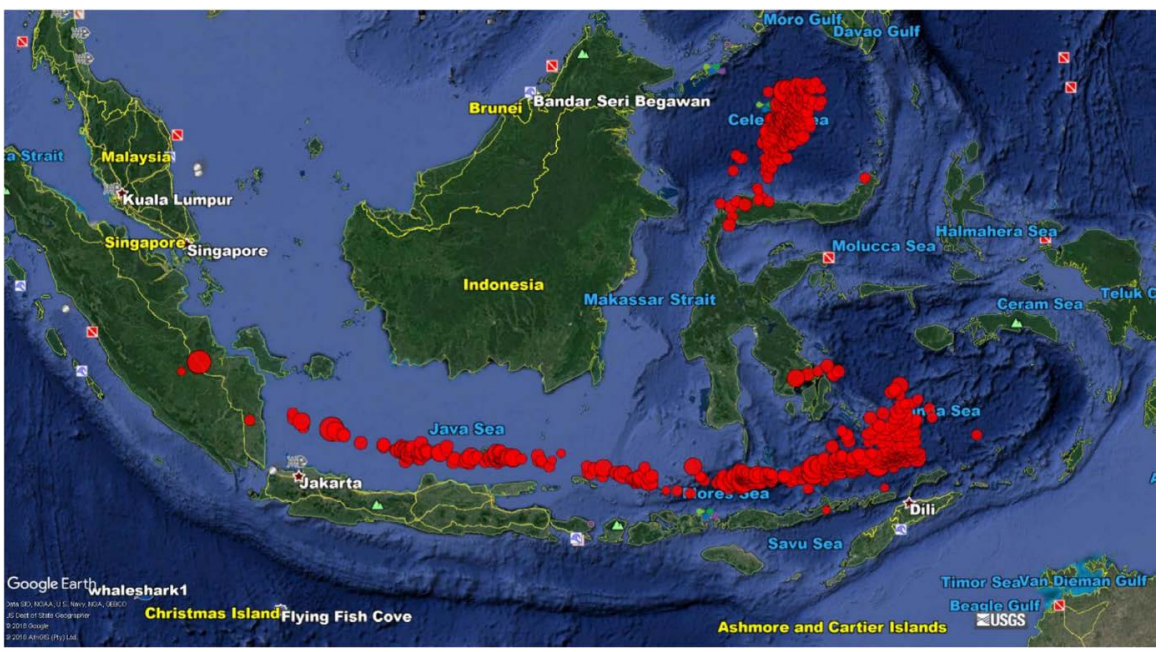

Figure 3. South Pacific, period 1950-2017, depth $\geq 500 \mathrm{~km}, \mathrm{M} \geq 2.5$. 
In the area surrounding Indonesia, there is a high concentration of tremors and many quakes in the Celebes Sea (see Figure 4).

The seas of Southern Indonesia presented a similarly high concentration for the most frequently-occurring events at $>500 \mathrm{~km}$ depths. For clarity, illustrating part of the Philippines together with Indonesia is what made identifying an accretion of quakes around these areas more noticeable. The deepest UDQ were in the Banda Sea at $674.3 \mathrm{~km}$ and in Mindanao at $678 \mathrm{~km}$.

The last area of examination is Fiji, which is experiencing subduction more quickly than the rest of the world $(10.5 \mathrm{~cm} / \mathrm{y})$ and is literally sinking below the oceanic plate. Although it is experiencing subduction more quickly, subduction zones are slower compared with the East Pacific's rise, which is splitting with speeds as $18.3 \mathrm{~cm} / \mathrm{y}$, and there are no occurrences of quakes at depths $>500 \mathrm{~km}$. There are two central regions for UDQ here, and they are northern Vanuatu and the area surrounding Fiji where depths $>670 \mathrm{~km}$ is not a rare occurrence (see Figure 5).

There were 126 recorded events around this location in the years from 1950-2017. Of these events, there were 12 quakes below $700 \mathrm{~km}$. The last one occurred in 2007.

On the other hand, the deepest occurrence was in the Vanuatu region in April 2004 with a depth below $700 \mathrm{~km}$. This unusual event in the area indicates there is unknown tectonics in this location. The other locations around the world presented with the deepest events offered $670 \mathrm{~km}$ as a limit; therefore, the tectonics around the concavity of Fiji and Tonga presented a strong anomalous depth for UDQ not shared by any other locations. It concluded the variation of UDQ events monthly by each subduction zone depended upon the tectonics in its area.

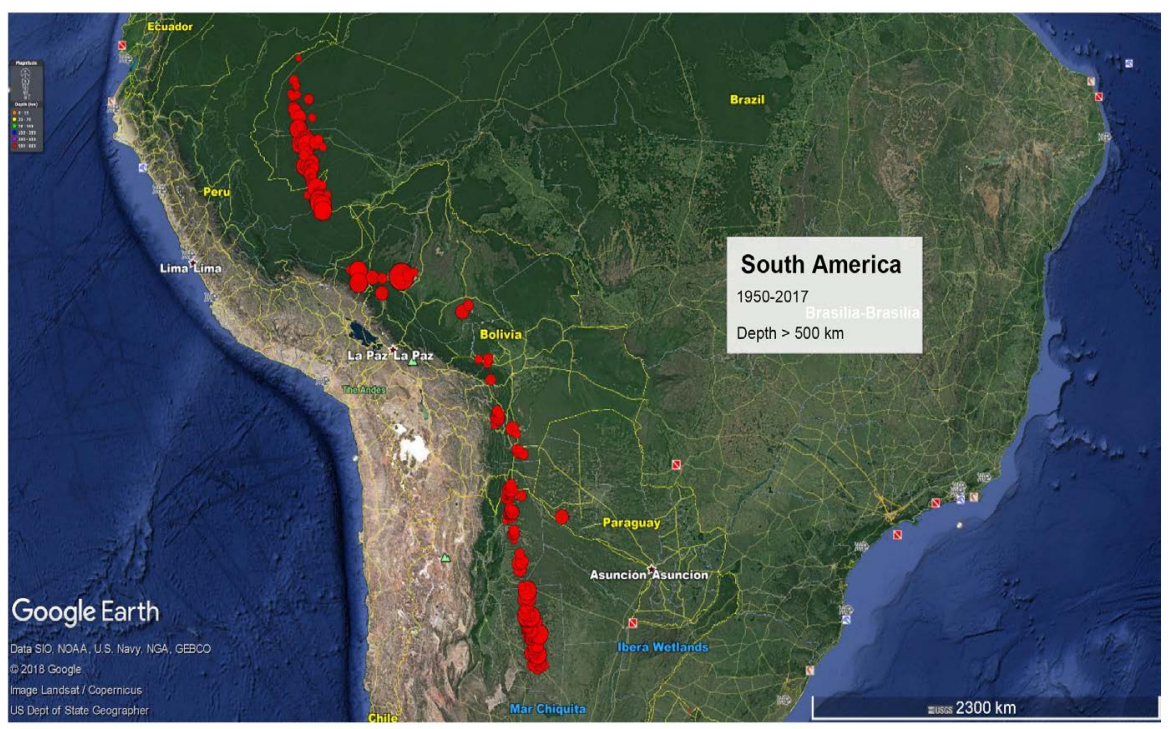

Figure 4. South America, period 1950-2017, depth $\geq 500 \mathrm{~km}$, magnitudes $\mathrm{M} \geq 2.5$ considered. 


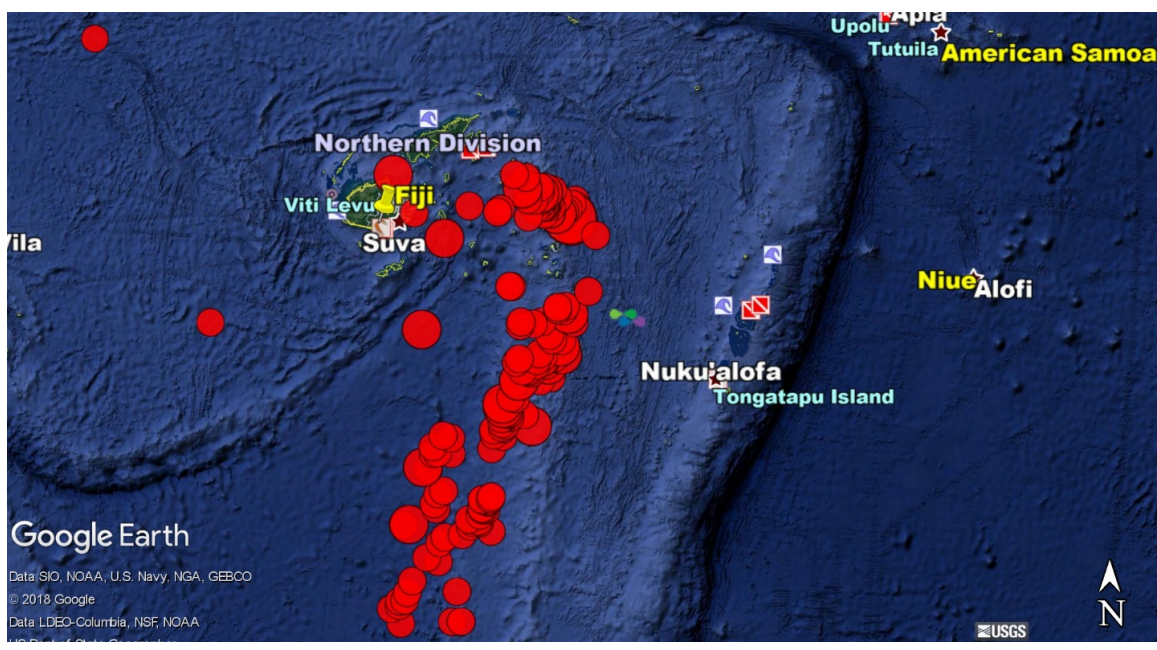

Figure 5. Fiji Islands, period 1950-2017, depth $\geq 500 \mathrm{~km}, \mathrm{M} \geq 2.5$.

\section{Mathematical Model Used}

Our method to determine whether the intensity and frequency of earthquakes increase, decrease, or remain constant in each region and depth was the following:

First, the areas with occurrences of earthquakes below $500 \mathrm{~km}$ were listed. We divided them into five centralregions: The North Pacific (Alaska, Japan, and Russia), Philippines, South Pacific (Australia, Indonesia, Samoa, and New Zealand), South America, and Fiji (including Vanuatu). Depending on the location, our data are: a magnitude of M6 and above at depths $\geq 500 \mathrm{~km}$ in the years from 1950-2017. The period is a sixty-eight-year interval and comprehends six Solar Maxima which occurred in 1958, 1968, 1979, 1989, 2008, and 2014 [10]. We constructed tables of $\mathrm{N}$ values for each month searched in the five locations. The records come from the catalogs at [8] and [9]. Then, we calculated the average of events for each month/location and presented the results (see Figure 6).

\subsection{Construction of Plots and Table 3}

The dataset comprises earthquakes recorded during the period from 1950-2017.

The data values were $\mathrm{y}_{1}=$ data recorded in the first-year level $\mathrm{n}$ (depth $\geq 500$ $\mathrm{km})$ in the region $\mathrm{X}(\mathrm{A}, \mathrm{B}, \mathrm{C}, \mathrm{D}, \mathrm{E})$.

$$
\sum_{n 0}^{n n} Y n=y n 0+y n 1+\cdots y n n^{\prime}
$$

where $n=1950 \cdots 2017$, and $n^{\prime}$ is 67 years.

The mean is defined as

$$
\text { Mean }=A=\frac{\sum_{n o}^{n n} Y n}{5}
$$

Data value - mean $=Y n^{\prime}[3]$.

If $Y_{n}^{\prime}>\mathrm{A}$, then the value is higher than one during that year and it means the number of earthquakes exceeds the average. On the other hand, if $Y_{n}^{\prime}<\mathrm{A}$ the number will be less than one during that year indicating that the number of 


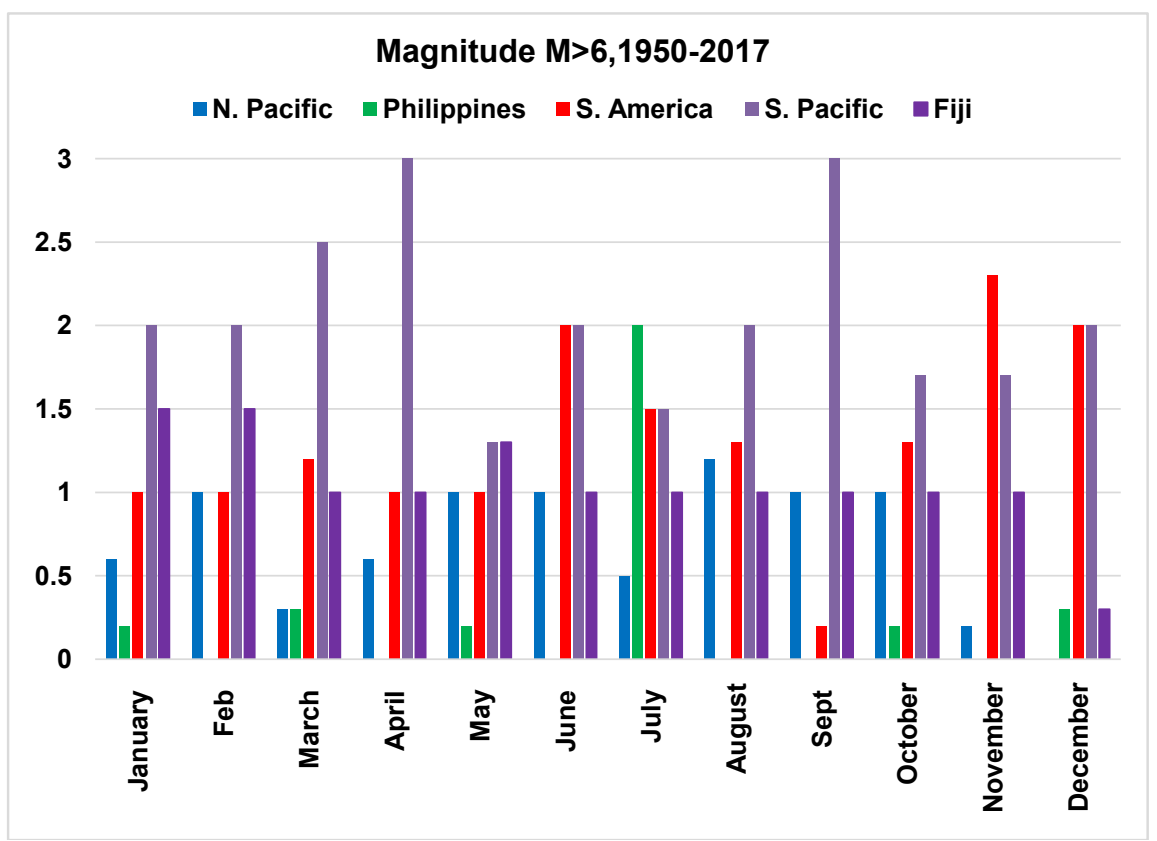

Figure 6. Data variation $M \geq 6$, period 1950-2017, depth $\geq 500 \mathrm{~km}$, worldwide.

Table 3. Quakes activity by months in each location, the description and correlations by seasons. Descriptions for the tectonics are in the text. Note that the season is dependent from the Hemisphere location.

\begin{tabular}{|c|c|c|c|}
\hline Locations & Active High & Active Low & None \\
\hline N. Pacific & $\begin{array}{c}\text { May (Spring) } \\
\text { August (Summer) }\end{array}$ & $\begin{array}{l}\text { March (Spring), } \\
\text { July (Summer), } \\
\text { November (Fall) }\end{array}$ & December (Winter) \\
\hline Philippines & July (Summer) & & $\begin{array}{c}\text { February (Winter), } \\
\text { April (Spring), } \\
\text { June/August } \\
\text { (Summer), Sept, Nov } \\
\text { (Fall) }\end{array}$ \\
\hline S. America & $\begin{array}{c}\text { August (Winter), } \\
\text { October/November } \\
\text { (Spring) }\end{array}$ & September (Spring) & \\
\hline S. Pacific & $\begin{array}{c}\text { March (Fall), August } \\
\text { (Winter), } \\
\text { October/November } \\
\text { (Spring) }\end{array}$ & July (Winter) & \\
\hline Fiji & $\begin{array}{l}\text { January, (Summer) } \\
\text { May (Fall), October } \\
\text { (Spring) }\end{array}$ & December (Summer) & \\
\hline
\end{tabular}

earthquakes was below the average in the area. It is also possible to have a result of zero, though this was not common in our dataset, which would mean there was no variation. Those calculations are made for each month and year for the location analyzed. The number five corresponds to the regions in the selected month and we constructed a plot with the monthly variation over the 67-year interval for each region analyzed. 


\subsection{General Results by Season and Region}

The quantitative results for this part of the research are displayed (see Figure 6) using the following initial conditions: magnitudes M6 and above, depth $\geq 500$ $\mathrm{km}$, and period 1950-2017. Data catalogs from the USGS and/or EMSC filter events by period, magnitude, and depths [8] [9]. The Appendix displays the results after all calculations.

The regions chosen were the North Pacific, Philippines, South America, South Pacific, and Fiji. Compared with the Southern Hemisphere, the Northern Hemisphere had lower activity levels and a lack of events during some months. The results in Table 3 describe each region, the activity as high, low, or none, and the period during which it happened.

Examining Table 3, the first two rows list high activity for UDQ at the Northern Hemisphere during the Summer, July or August, while low activity happened only to North Pacific areas. In December, there was an absence of quakes in North Pacific. The next is Philippines where the activity for July is the highest observed than in any other location. Philippines is the area with no activity during five months of the year (February, April, June, September, and November). Regarding the Northern Hemisphere, it would be almost sure that a big earthquake is likely to happen in July (High Summer) in such a location.

The Southern Hemisphere was more complicated than the Southern Pacific where higher activity happened March, (Fall), August (Winter), and October/November (Spring).

In South America, the high activity is August (Winter) and October/November (Summer). Finally, Fiji has great activity in January (Summer) and May (Fall). October (Spring) is the only month in which the probability of UDQ M6 events happening is low. It is interesting to observe the months without activity did not occur in the Southern Hemisphere.

Table 3 and Figure 6 gave us an idea of what to expect regarding the number of shocks during each month and, consequently, in which season it is more likely to happen. As a result, it was possible to distinguish among the regions and the months when the hazard is likely to occur more often at a higher magnitude.

This established that only the Northern Hemisphere had months without quakes and/or experienced large magnitude quakes at the lowest proportion. It illustrated these variations among the years and differences for each region are a product of both the seasons and the tectonics involved, at least for such deep depths. The next calculations are how each area responds to the frequency of the event depending on the month.

\section{Events $M \geq 6$, Ultra-Deep Quakes (UDQ) by Area}

\subsection{North Pacific Monthly Variations}

This area was evaluated over 67 years for quakes $M \geq 6$ by month. The results showed that May or August (Spring and the end of Summer) had the highest number of occurrences. Summed, they account for $42 \%$ of the activity in the 
area. This equated to almost half of the quake occurrences of this magnitude and depth in the area. There was a total absence of earthquakes in December in the period searched (see Figures 1-7).

\subsection{Philippines Monthly Variations}

The region situated near the equator presented an astonishing increase of 50\% in the number of quakes with $M \geq 6$ that took place in July, which corresponds to High Summer in the area. Five months: January, March, May, October, and December, accounted for the other $50 \%$ of activity. The other months did not have a significant number of quakes satisfying the criteria (see Figure 2 and Figure 8).

\subsection{South Pacific Monthly Variations}

The highest number of earthquakes in this area occurred at the end of Winter in August (13\%) followed by early Fall in March (11\%). Although there are different subduction zones at this point, it was impossible to separate the events because the occurrences are fewer for UDQ in each zone; however, it is likely the tectonic involved is responsible for the activity at several points (see Figure 3 and Figure 9).

\subsection{South America Monthly Variations}

In this area, the enhancement of quakes occurred most at the end of Winter in August and in Spring in November, followed by the end of Spring in October. At the same location, there seems to be uneven tectonics compared to the areas where the most quakes occurred (see Figure 4).

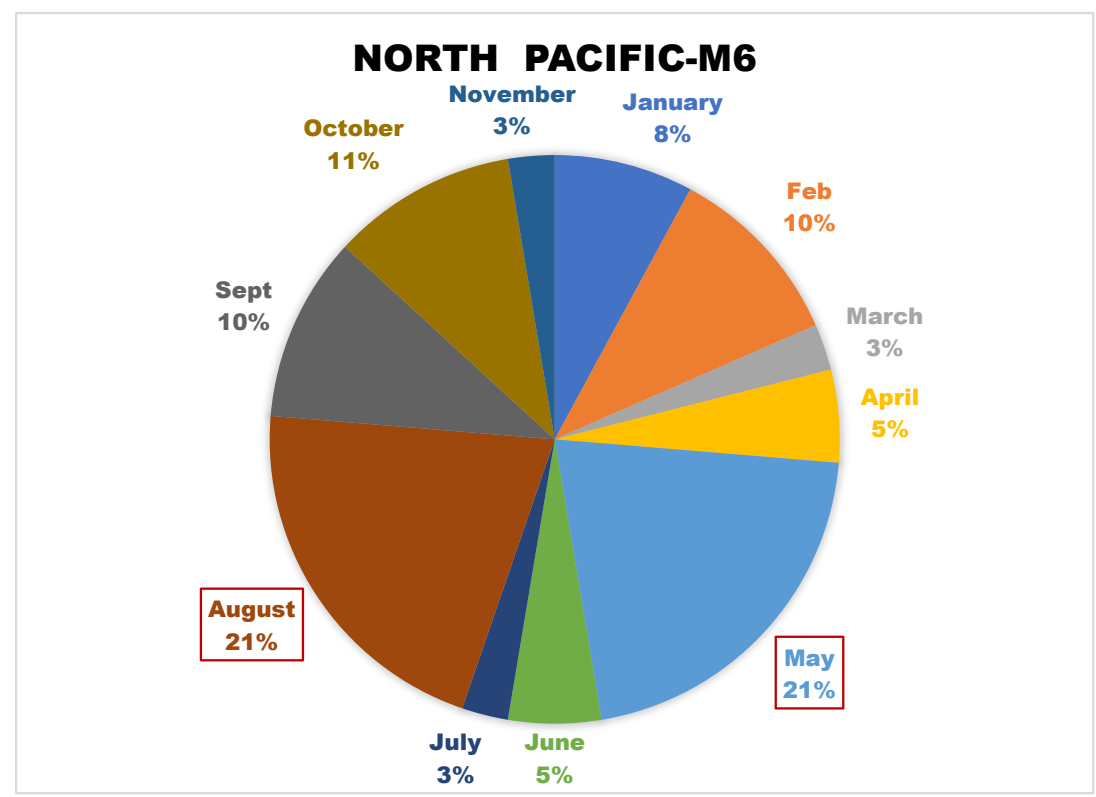

Figure 7. North Pacific variation along the year, for quakes M6 or above, period 1950-2017, depth $\geq 500 \mathrm{~km}$. 


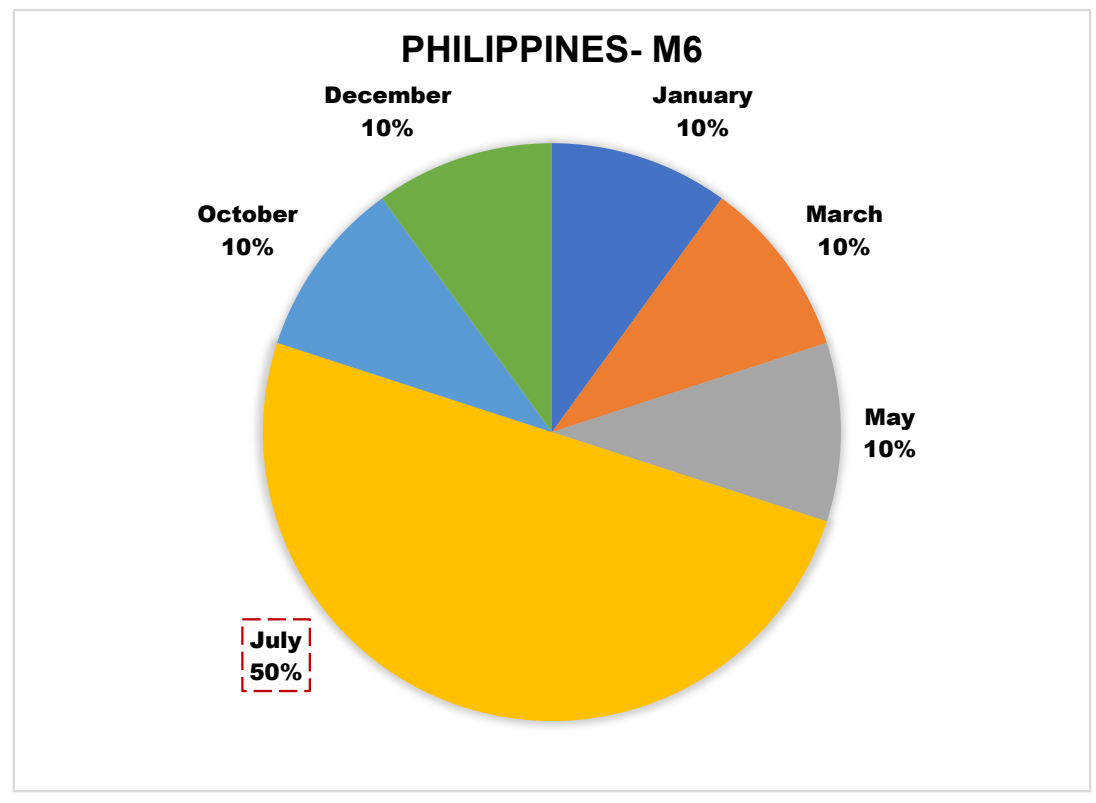

Figure 8. Philippines, M6 or above period 1950-2017, depth $\geq 500 \mathrm{~km}$.

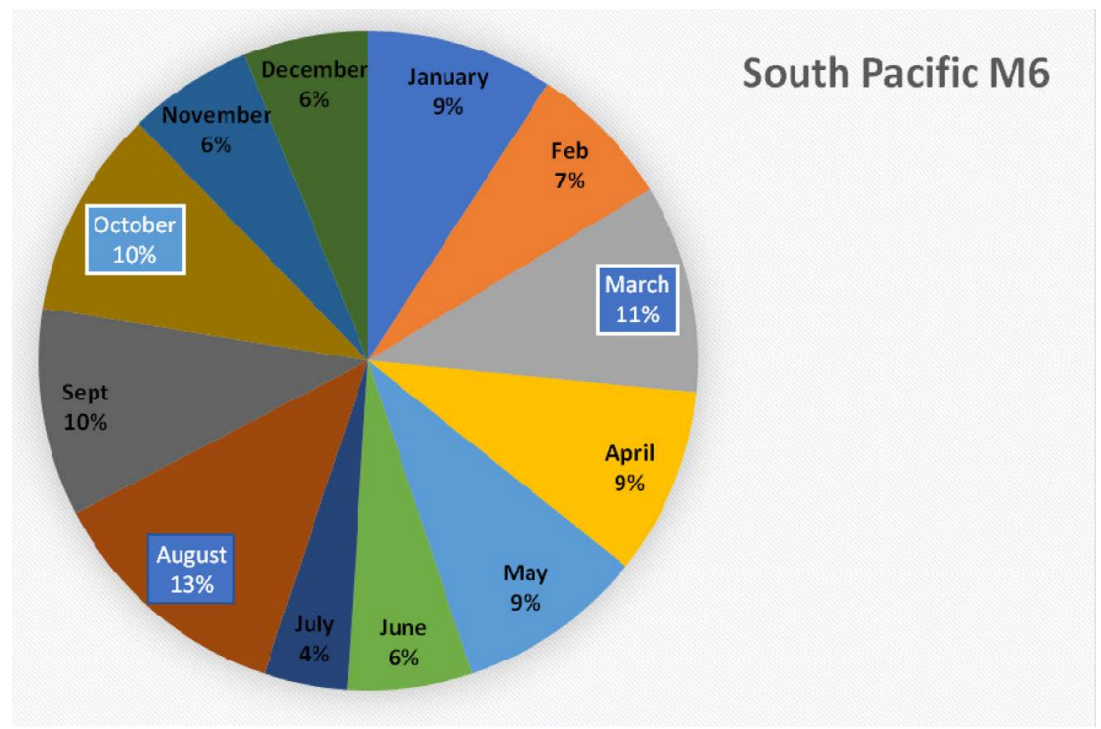

Figure 9. South Pacific quakes M6 or above, period 1950-2017, depth $\geq 500 \mathrm{~km}$.

Clearly, in this area of South America, inside of the continent, there was a gap between the Northern part of the occurrences and the Southern part (see Figure 10).

\subsection{Fiji Monthly Variations}

In some respects, this case is like South America, as the increases occurred at the end of Fall in May (19\%), followed by the Summer in January (15\%), and finally during the Spring in October (12\%). The similarity is because in South America there are two regions that accumulated a greater number of quakes with the highest magnitude, which happened around the North Fiji Basin and other 


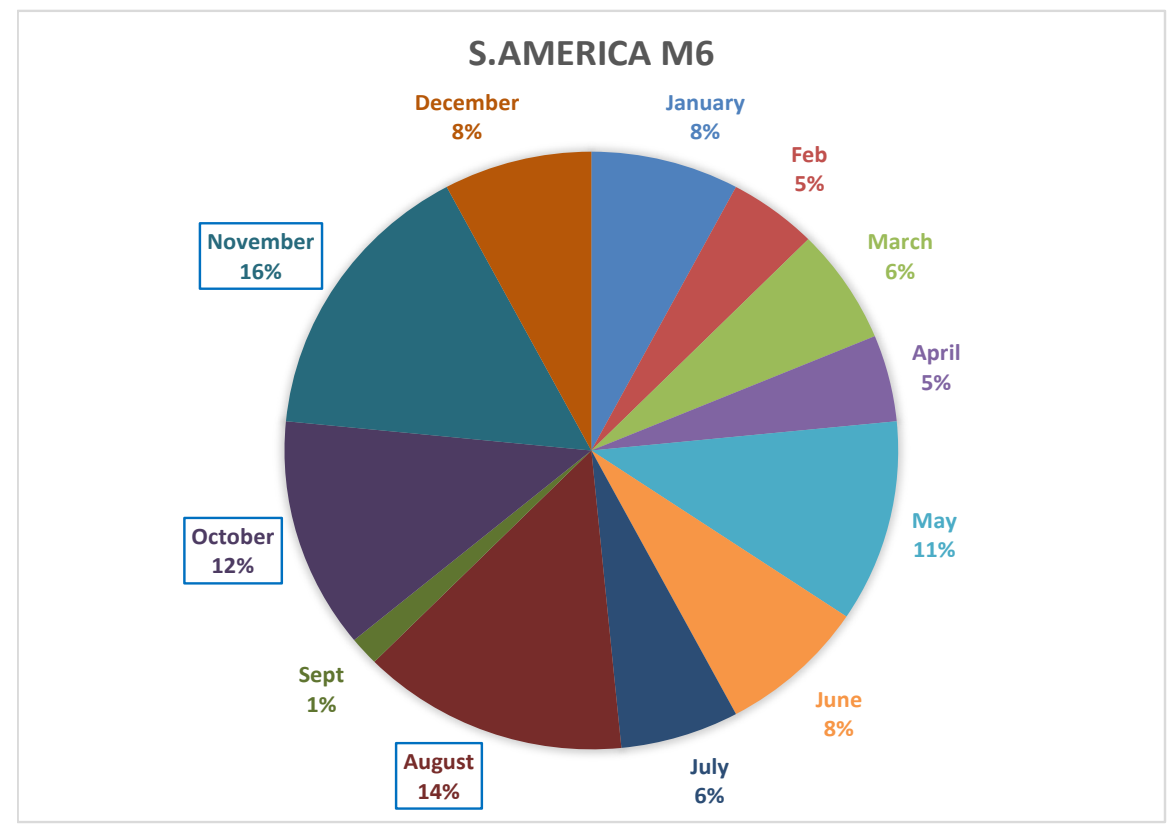

Figure 10. South America, M6 or above, depth $\geq 500 \mathrm{~km}, 1950-2017$.

lower zone, as you can observe comparing Figure 4 and Figure 5 and following the percentage from Figure 11. The results found in this paper indicate some points in the region analyzed produced a higher number of earthquakes at $M \geq 6$ than others. This would mean there are areas where the tectonics are auspicious to the occurrence of events; however, it could also mean the same regions would permit a higher number of smaller earthquakes instead of the biggest ones for which we inquired.

\section{Final Discussion}

Our results found out that the seasonality ofUDQ is codependent with the location examined. Table 3 shows, for the Northern Hemisphere quakes, enhancement to the North Pacific happened May (Spring) and August (Summer) are responsible for $42 \%$ of M6 or higher UDQ. Philippines had an increase to UDQ magnitude $M \geq 6$ during July (High Summer) with $50 \%$ of occurrences; there is a lack of occurrences for six months in this area.

To the Southern Hemisphere is a scenario change; South Pacific presented highest probabilities of occurrences at 33\% in August (Winter), September and October (Spring). South America has August (Winter), October and November (Spring) with a total of $42 \%$ of occurrences. Finally, Fiji enhancements happened the January (Summer), May (Fall), and October (Spring) performing $46 \%$ of the events.

Overall, the Northern Hemisphere had a good chance of events happening during the Summer and the Southern Hemisphere had October as a leader of occurrences in all areas.

Those results pointed out that Summer is an UDQ season for the Northern Hemisphere and Spring is likely to be important to the Southern Hemisphere. 


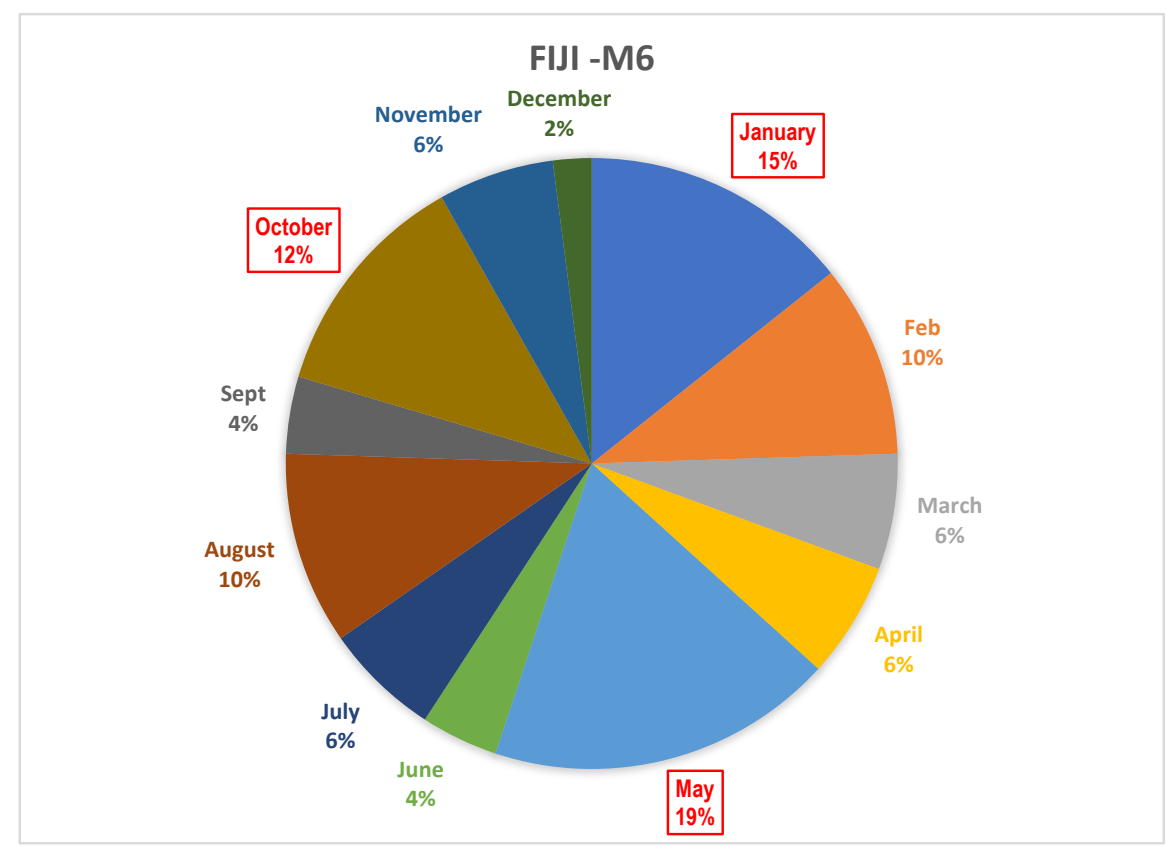

Figure 11. Fiji region, period 1950-2017, M6 or above, depth $\geq 500 \mathrm{~km}$.

Obviously, the results show that seasons for the events depend on the subduction place analyzed. The season variations are considered external factors in Earth's environment and would be responsible for the alterations observed in the data, but the tectonics of each area researched seem to contribute to the seasonality of each area studied.

The development of this paper, with the additional factor for the tectonics, pointed out that not only the season but also the geophysical environment is able to increase or decrease the number of UDQ events for magnitudes $M \geq 6$.

\section{Conclusion}

This investigation tried to find out a possible seasonality for earthquakes in five different regions with some initial conditions such as magnitude, UDQ events, and dividing areas according to the different tectonics. We found better correlations to the Northern Hemisphere than to the Southern Hemisphere and, apparently, it is related to the details of the tectonics in each region. Particularly, Fiji-Vanuatu presented the most important discrepancies from other areas and the aim of a next paper is to discuss why this happens with more detail.

\section{Conflicts of Interest}

The authors declare no conflicts of interest regarding the publication of this paper.

\section{References}

[1] Hagen, M. and Azevedo, A. (2018) Deep and Ultra-Deep Earthquakes Worldwide, Possible Anomalies in South America. Natural Science, 10, 199-213. 
https://doi.org/10.4236/ns.2018.106022

[2] Hagen, M. and Azevedo, A. (2018) Possible Connections between Seasons and Ultra-Deep Earthquakes Worldwide. Natural Science, 10, 288-302. https://doi.org/10.4236/ns.2018.107029

[3] Zhan, Z. and Shearer, P. (2015) Possible Seasonality in large Deep-Focus Earthquakes. Geophysical Research Letters, 42, 1-8.

[4] Yoshio, F. and Masyuki, O. (2013) Subducted Slabs Stagnant Above, Penetrating Through and Trapped below the $660 \mathrm{~km}$ Discontinuity. Journal of Geophysical Research: Solid Earth, 118, 5920-5938. https://doi.org/10.1002/2013JB010466

[5] Hamburger, M.W. and Isacks, B.L. (1987) Deep Earthquakes in the Southwest Pacific: A Tectonic Interpretation. Journal of Geophysical Research, 92, 13841-13854. https://doi.org/10.1029/JB092iB13p13841

[6] Richards, S., Holm, R. and Barber, G. (2011) When Slabs Collide: A Tectonic Assessment of Deep Earthquakes in the Tonga-Vanuatu Region. Geology, 39, 787-790. https://doi.org/10.1130/G31937.1

[7] Bonnardot, M.A., et al. (2009) Seismological Evidence for a Slab Detachment in the Tonga Subduction Zone. Tectonic Physics, 464, 84-99. https://doi.org/10.1016/j.tecto.2008.10.011

[8] https://earthquake.usgs.gov/earthquakes/search/

[9] https://www.emsc-csem.org/Earthquake/?filter=yes

[10] Hagen, M. and Azevedo, A. (2017) Possible Connections between X-Solar Flares and Worldwide Variation in Seismicity Enhancement. Natural Science, 9, 457-476. https://doi.org/10.4236/ns.2017.912042 


\section{Appendix}

It is calculated the average of UDQ for each month and compared with the other locations.

\begin{tabular}{cccccc}
\hline Areas & N. Pacific & Philippines & S. America & S. Pacific & Fiji \\
\hline January & 0.6 & 0.2 & 1 & 2 & 1.5 \\
Feb & 1 & 0 & 1 & 2 & 1.5 \\
March & 0.3 & 0.3 & 1.2 & 2.5 & 1 \\
April & 0.6 & 0 & 1 & 3 & 1 \\
May & 1 & 0.2 & 1 & 1.3 & 1.3 \\
June & 1 & 0 & 2 & 2 & 1 \\
July & 0.5 & 2 & 1.5 & 1.5 & 1 \\
August & 1.2 & 0 & 1.3 & 2 & 1 \\
Sept & 1 & 0 & 0.2 & 3 & 1 \\
October & 1 & 0.2 & 1.3 & 1.7 & 1 \\
November & 0.2 & 0 & 2.3 & 1.7 & 1 \\
December & 0 & 0.3 & 2 & 2 & 0.3 \\
\hline
\end{tabular}

